\title{
Employee perceptions of risks and rewards in terms of corporate entrepreneurship participation
}

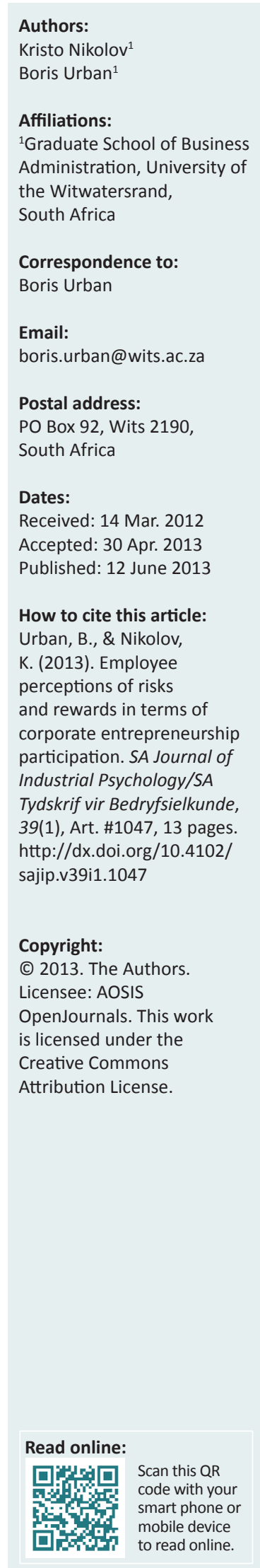

Orientation: Early studies recognise how important corporate entrepreneurship (CE) is to achieving sustainable competitive advantage.

Research purpose: With the scope of CE widening, organisations that lack prior entrepreneurial recognition are adopting $\mathrm{CE}$ in order to survive and succeed in increasingly competitive and financially constrained environments.

Motivation for the study: By using conjoint analysis, the study is able to determine empirically which criteria organisations use, when they decide to participate in CE activities, are significant.

Research design, approach and method: The authors used conjoint analysis. It simulates real life situations where it presents and tests various scenarios in terms of combinations of attributes and levels of intensity that influence decisions to participate in CE.

Main findings: The results show that the most important attribute that influences the decision to participate in $\mathrm{CE}$ is the probability of venture success. Financial reward follows closely. As expected, job risk, pay risk and exerted effort are deterrents to CE participation.

Practical/managerial implications: The study provides guidance to managers and leaders interested in motivating their employees to undertake $\mathrm{CE}$ activities. The results give direction to employees by offering them different scenarios of incentives and commensurate risks when they participate in CE.

Contribution/value-add: This is one of the first studies to test empirically the likelihood of CE participation in terms of conjoint analysis. It provides managers with a dashboard of possible attributes, according to which they can devise optimal incentive strategies.

\section{Introduction}

\section{Key focus of the study}

Many firms are adopting corporate entrepreneurship (CE) as a way of combating the lethargy and bureaucracy that often accompany business size and cultural lock-ins (Burns, 2004). Schindehutte, Morris and Kuratko (2000) point out that a spirit of entrepreneurship needs to permeate organisations. It is essential to ensure that a continuous flow of innovation and entrepreneurship becomes a specialised function in organisations.

\section{Background to the study}

Firms increase the chances of success of CE strategies if they have the necessary skills to structure (accumulate and strategically divest), bundle (successfully combine), and use (mobilise and deploy) their resources (Sirmon, Hitt \& Ireland, 2007). Appointing people or teams that drive and stimulate entrepreneurial activities, like creating new ventures, culminate in active change where organisational support and self-efficacy play crucial roles for employees who are willing to take charge in organisations (Onyishi \& Ogbode, 2012).

\section{Trends from the research literature}

In recent years, CE has been the focus of considerable research activity (Covin \& Kuratko, 2008; Ireland, Covin \& Kuratko, 2009; Phan, Wright, Ucbasaran \& Tan, 2009). With the scope of CE widening, organisations that lack prior entrepreneurial recognition are adopting CE in order to survive and succeed in increasingly competitive and financially constrained environments (Antoncic, 2006; Kuratko \& Audretsch, 2009; Neill \& York, 2011; Phelps, 2009). CE usually refers to organisations' commitments to pursuing new opportunities, creating new units or businesses, being innovative in terms of products, services and processes, strategic self-renewal, constructive risk-taking and being pro-active (Antoncic \& Hisrich, 2004).

Previous research on CE focuses on the attributes that promote entrepreneurial activities. However, it ignores, to some extent, the participation of individual employees and of groups of 
employees that could promote CE in organisations (Kuratko, Ireland, Covin \& Hornsby, 2005). Hornsby, Kuratko, Shepherd and Bott (2009) propose that managers at various levels have different roles that provide a form of structural ability to implement entrepreneurial ideas.

Organisations that pursue CE strategies are likely to exhibit a cascading, yet integrated, set of entrepreneurial activities at the senior, middle and lower levels of management, with managers at the different levels sharing joint responsibility for their organisations' entrepreneurial activities (Hornsby et al., 2009). One often attributes the success of ventures, which practise CE, to the keen participation and specialised skill sets that certain managers and employees bring to the ventures (Hornsby, Kuratko \& Zahra, 2002). A sense of coherence often determines employees' perceptions of the helping and restraining forces in organisations (Muller \& Rothmann, 2009). The combination of knowledge, skills and judgements of interested and committed employees and managers ensures the success of CE initiatives (Allen, Lucero \& Van Norman, 1997).

Recent research confirms that understanding motivational rewards and risks is important to understanding $\mathrm{CE}$ participation (Hornsby et al., 2009). This is especially true when decisions to participate in $\mathrm{CE}$ initiatives includes various rewards such as financial incentives, opportunities for future growth, intrinsic rewards like feelings of achievement and satisfaction from completing interesting and challenging work as well as increased decision-making autonomy. Furthermore, deterrents to participation include job risk, pay risk, risk of failure, unavoidable costs and extra effort requirements (Arnolds \& Venter, 2007).

\section{Brief overview of corporate entrepreneurship}

There are various descriptions of entrepreneurship in corporations. They have conceptual roots in innovation entrepreneurship (Schumpeter, 1934) and innovation management (Drucker, 1979). More recent terms include intrapreneurship (Antoncic \& Hisrich, 2001; Pinchot, 1985), venture entrepreneurship (Tang \& Koveos, 2004), corporate intrapreneurship (Dess et al., 2003), strategic entrepreneurial posture (Covin \& Slevin, 1989) and internal corporate venturing (Hornsby, Kuratko \& Zahra, 2002).

Literature has conceptualised CE as a multidimensional phenomenon that incorporates the behaviour and interactions of the individual, organisational and environmental elements in organisations (Covin \& Miles, 2007; Dess, Lumpkin \& McGee, 1999; Kuratko, Hornsby, Naffziger \& Montangno, 1993; Morris, Davis \& Allen, 1994; Morris \& Kuratko, 2002; Zahra, 1993). CE activities include strategic renewal (organisational renewal that involves major strategic and/ or structural changes), innovation (introducing something new to the marketplace) and corporate venturing (corporate entrepreneurial efforts that lead to the creation of new companies within the corporate company. All of these are important and legitimate parts of the CE process (Covin
\& Miles, 1999; Kuratko \& Welsch, 2001; Morris \& Kuratko, 2002; Neill \& York, 2011).

Popular methods for evaluating the level of CE in organisations include the corporate entrepreneurship assessment inventory (Hornsby et al., 2002), entrepreneurial management (Brown, Davidsson \& Wiklund, 2001) and a distinct construct of entrepreneurial orientation (Covin \& Slevin, 1989; Khandwalla, 1977). All of them include the principle of rewards or reinforcement as a key determining attribute.

\section{Participation in corporate entrepreneurship initiatives: Risk and rewards}

Earlier models have recognised the importance of participating in CE initiatives because CE sustainability depends on individual employees who undertake innovative activities that stimulate positive perceptions in top-level managers. This, in turn, leads to further allocations of necessary organisational support and resources (Kuratko, Hornsby \& Goldsby, 2004; Hornsby et al., 2009). Top level managers are responsible for establishing proentrepreneurship organisational architectures where the workplace exhibits structural, cultural, resource and system attributes that encourage entrepreneurial behaviour, both individually and collectively (Morris, Kuratko \& Covin, 2008; Schindehutte et al., 2000). Several South African studies confirm that an organisational culture, which promotes trust, is critical to promoting participation in creativity and innovation (Martins \& Martins, 2002; Odendaal \& Roodt, 1998).

The few studies (primarily conceptual) that have explored managerial levels have emphasised the role of first-level managers in a 'bottom-up' process of CE (Burgelman, 1983; Valoyi, Lessing \& Schepers, 2000). On the other hand, research suggests a counter weight to this 'bottom-up' process with arguments and empirical evidence that supports the notion that, given a specific organisational environment, senior managers have greater structural ability to 'make more of' the conditions and implement a greater number of entrepreneurial ideas than do first-level managers (Morris, Kuratko \& Covin, 2008).

One of the major requirements for developing $\mathrm{CE}$ organisational architecture is the appropriate use of rewards (Damanpour, 1991; Hornsby et al., 2002; Ireland et al., 2009). In most human resource practices, the basic principle is that practices that differ in kind are complementary for sustaining innovation, in particular those that infuse powerful individual incentives co-applied with practices that infuse team spirit and organisational identification (Grandori, Giordani \& Hayton, 2011; Phan et al., 2009). Encouraging risk-taking and innovative behaviours must be consistent with individualised performance assessment and compensation (Kuratko, Morris \& Covin, 2011), particularly because human resources management practices can affect CE initiatives in different ways (for an in-depth overview on CE and human resource management (HRM), see Kuratko et al., 2011). 
The availability of resources, a supportive organisational structure and a culture that tolerates failure are all attributes that motivate employees to participate in CE schemes (Hornsby et al., 2002; Ireland et al., 2009). The availability of resources tells employees that projects have sufficient funding for activation and are not at risk of premature cancellation, whilst a failure-tolerant organisational culture indicates that failure is necessary for learning and improvement rather than a reason for dismissal.

Both are signals that tend to reduce the risk of participation in employees' minds, particularly as risk is often a deterrent to participation in CE ventures. Allen, Lucero \& Norma (1997) suggest that participants join employee involvement programmes when they are beneficial and not harmful to their interests and where personal and organisational rewards are often motivators for joining (Verma \& McKersie, 1986).

Personal rewards can be intrinsic - like opportunities to demonstrate and use underutilised knowledge and skills. Extrinsic rewards include impressing managers, thus positioning one's self for advancement and being a part of processes that will improve organisational functioning (Miller \& Prichard, 1992).

Individual-level autonomy provides the flexibility and freedom to pursue novel or interesting ideas, often for their own sake. This individual experimentation and exploration are often the first steps in the sequence that leads from innovation to establishing new ventures (Grandori et al., 2011). People may also change incrementally by retaining their jobs whilst becoming self-employed.

This hybrid entrepreneurship corresponds to increased emphasis on nonstandard work arrangements. They may be particularly useful to highly capable people who lack entrepreneurial experience (Folta, Delmar \& Wennberg, 2010). In addition, people who yearn to satisfy a higher order need are more likely to participate in CE programmes. Allen et al. (1997) suggest that organisations should not encourage people to participate in CE programmes unless their involvement meets their intrinsic needs and interests. If employees cannot see a clear link between effort and performance, and between performance and reward, they may remain unwilling to participate in CE initiatives (Kuratko et al., 2011).

Employees face potential rewards when they participate in $\mathrm{CE}$ ventures. However, they also face deterrents, where organisations often expect employees to dedicate long hours and increased effort in order to make $C E$ ventures successful. Agency theory assumes that employees feel differing degrees of aversion to work effort (Douglas \& Shepherd, 2002). The literature suggests that employees, who are dedicated to the success of CE ventures, will work longer hours than their peers will but experience more stress (Sykes, 1992; Monsen et al., 2010).
Aside from rewards and risks, employees are also less likely to participate if they sense that managers are not sincere in their commitment to CE programmes or if they feel that companies do not have the resources to take the initiative through to success (Allen et al., 1997). Internal entrepreneurs, or intrapreneurs, have reduced exposure to financial risk as they rarely invest their own financial resources. Nevertheless, they still invest their own human capital and expose themselves to career risk when they participate in $\mathrm{CE}$ ventures. The success or failure of the $\mathrm{CE}$ ventures to which they contribute may reflect positively or negatively on their reputations and influence access to future and more rewarding positions (Morris et al., 2008).

Furthermore, in a CE context, the main risks include personal reputation, possible lack of career advancement, demotion, lowered social status and job loss as indirect threats (Sykes, 1992). Organisations have differing views about failure. Whilst some firms might not want to retain employees who participated in failed ventures, others see them as valuable management development experiences. Even if firms hold the latter view, time spent in failed CE ventures is a lost opportunity for advancement or promotion - and employees perceive it as risk (Antoncic, 2003; Sykes, 1992).

\section{Research objectives}

From a practical standpoint, and in line with calls for further research (Hornsby et al., 2009), this study argues that future applications of CE participation need to concern themselves with two key issues. The first is the perception of managers and employees about reward and risk attributes that precipitate CE activities. The second is the characteristics of people who are likely to influence decisions to participate in $\mathrm{CE}$ activities. Furthermore, western economies have recorded the advantages of $\mathrm{CE}$, market and learning orientation extensively. However, there is little research on improving these critical competitive practices in emerging economies (Liu, Luo \& Shi, 2003; Urban, 2011).

Because of the relative dearth of research on the attributes that influence employee participation in CE, this study considers the personal attributes that promote or hinder CE activity. A deep and thorough understanding of $C E$ is important for academic purposes. It is also relevant for practitioners and policy makers. These implications relate to profitability and competitiveness as well as to the overall economic performance of industry and the national economy (Bosma \& Harding, 2006).

By using conjoint analysis, the study is able to determine empirically which criteria organisations use in their decisions to participate in CE activities are significant (Shepherd \& Zacharakis, 1997). The study achieves this by:

- Measuring the relative importance that one can attribute to CE participation. The study proposes that there is a significant positive correlation between the mean partworth utilities one can attribute to sharing incentives and expectations of success and that there is a significant 
negative correlation between the mean part-worth utilities one can attribute to job risk, pay risk and exerted effort.

- Using conjoint analysis. This is an underutilised method in management and entrepreneurship research (Lohrke, Holloway \& Woolley, 2010). However, it has the advantage of dividing decision-making processes into underlying respondent preferences for attributes.

- Assembling a sample of over 140 employees and managers at different organisational levels in an under-researched geographical emerging market area - Johannesburg, South Africa.

- Providing preliminary evidence that the attributes of rewards and risks influence the decision to participate in CE activities.

The methodology of this paper relies on using dichotomous manipulations (high and low levels of intensity) (Monsen, Patzelt \& Saxton, 2010). This allows one to model the various effects of attributes like potential rewards, perceived venture success probability, necessary effort and risks that may influence the willingness of employees and managers to participate in CE activities.

Respondents choose from various scenarios. They analyse several attributes in different combinations in terms of their intensity levels. By using conjoint analysis, the selected methodology resembles real life situations more closely than questionnaires or interviews do because it places respondents in situations where several attributes come into play when they make decisions (Orme, 2009).

From academic and practitioner perspectives, the paper contains important implications where empirical evidence will contribute to building theory in the CE domain and provide practical guidance on how to optimise rewards as well as to reduce risks by using a dashboard of possible attributes to encourage CE participation.

\section{Hypotheses}

The authors developed their research hypotheses from past theory and research. Figure 1 provides a graphic representation of the hypotheses, which delineates reward and risk variables as well as their expected effects on employees' decisions to participate in CE initiatives.

The horizontal axis presents the employees' decisions to participate (right) or not to participate (left). High expectations of venture success and financial rewards will increase the probability of participating. Similarly, there are deterring forces, represented by pay risk, employment risk and extra effort, which will lower the probability of participation.

The model includes the participants' characteristics of entrepreneurial experience, gender and years of work experience. They may act as motivators of, or as deterrents to, the decisions to participate.

The next section discusses the attributes in this model further with reference to each hypothesis.

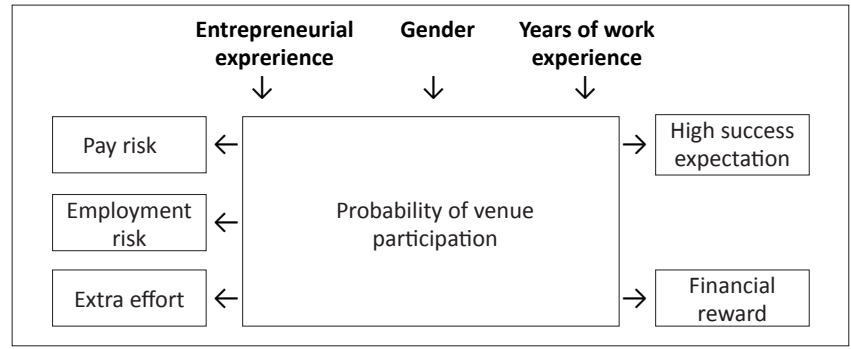

FIGURE 1: Proposed attributes that influence employee participation in corporate entrepreneurship initiatives.

Financial reward. This attribute gives the magnitude of financial gain that employees could expect from participating in $\mathrm{CE}$ ventures. One of the major elements in developing pro-entrepreneurship organisational architecture is reward (Hornsby et al., 2002; Ireland et al., 2009). One would normally expect that the prospect of higher financial gain would be a prime motivator for participation in CE activities (Fehr \& Schmidt, 2007).

Venture success probability. This attribute refers to the perception that employees have that $C E$ ventures will succeed. Expected CE success gauges participation. The availability of resources, a supportive organisational structure and a culture that tolerates failure, all indicate that success is highly probable (Hornsby et al., 2002; Ireland et al., 2009). In these circumstances, a pro-entrepreneurship organisational architecture (Ireland et al., 2009) will increase perceptions of the probability of CE success. Participants can sense if managers are not sincere in their commitment to $C E$ initiatives or if the necessary resources are unavailable to take the initiatives through to success (Allen et al., 1997).

Employment risk. This attribute refers to the likelihood of employees losing their jobs in the event that CE initiatives fail. A failure-tolerant organisational culture indicates that failure is necessary for learning and improvement rather than a reason for dismissal. It tends to reduce the risk of participation (Allen et al., 1997). Consequently, depending on the firms' cultures and circumstances, the perceived risk may be higher or lower. Employees usually derive a disutility from risk. Therefore, the rational expectation for any human being would be to attempt to reduce personal risk and maximise personal gain (Douglas \& Shepherd, 2002).

Pay risk. This attribute is similar to employment risk. It is an attribute that refers to an outcome that follows the failure of $C E$ initiatives. In this particular instance, pay risk refers to reduced remuneration (demotion) for employees if the ventures fail. High pay risk could demotivate employees from participating in CE initiatives because participation could introduce undesirable outcomes (Douglas \& Shepherd, 2002).

Exerted effort. This attribute refers to the extent to which additional working hours affect employees' willingness to participate in CE initiatives. Douglas and Shepherd (2000, 2002) found that work effort has a negative relationship with employees' decisions to become self-employed. These authors explain that employees derive disutility or 
dissatisfaction from having to exert extra effort and that selfemployed people are less averse to work effort.

In the context of $\mathrm{CE}$, often when employees are working on new initiatives, the challenges are more demanding than those that employees normally face in their day-to-day work. However, efforts beyond the norm, and hours worked above regular working hours, represent disutility to employees, which they want to avoid (Douglas \& Shepherd, 2000). The employees involved in the CE ventures see extended working hours as lost opportunity costs. These opportunity costs could come in variety of forms, like time spent with families, second jobs, hobbies and improved education qualifications (Amit, Muller \& Cockburn, 1995; Cassar, 2006).

Individual characteristics. The demographic characteristics of participants estimate the likelihood of participation because different characteristics affect choices to participate or not to participate in CE initiatives. Allen et al. (1997) find that people who volunteer for CE-type programmes are usually more senior (Barrick \& Alexander, 1987; Norris \& Cox, 1987), better educated (Norris and Cox, 1987), more ambitious (Miller \& Prichard, 1992), better performers (Barrick \& Alexander, 1987), have higher self-esteem and have a greater desire to participate in making decisions (Buch, 1991). Consistent with recent studies, the characteristics that are most likely to influence CE participation include gender (Baum \& Locke, 2004), past entrepreneurial experience (Folta et al., 2010; Nanda \& Sorensen, 2010) and number of years of work experience (Dess et al., 2003).

Drawing on these various attributes of rewards and risks, as well as the characteristics that may influence CE participation, the authors formulated two hypotheses.

Hypothesis 1. There are significant differences in the mean part-worth utilities one can attribute to participation in CE. There is a significant positive correlation between the mean part-worth utilities one can attribute to financial rewards and expectations of success, whilst there is a significant negative correlation between the mean part-worth utilities one can attribute to job risk, pay risk and exerted effort. The participants' gender, past entrepreneurial experience and number of years of work experience are the basis for these correlations.

In line with the study objectives, the authors used conjoint analysis to test the hypothesis. This approach allowed them to build onto existing research by assessing how trade-offs are made amongst different criteria when making decisions (Lohrke, Holloway \& Woolley, 2010; Shepherd, 2011). The respondents received various scenarios where several attributes featured in different combinations in terms of specified intensity levels.

The respondents rated these scenarios on a scale of 1-7 in terms of the likelihood of participation in CE initiatives. Using multiple regression analysis, the data provided the preference scores, or part-worth utilities, for each attribute.
Consequently, the authors formulated a combination hypothesis. It incorporated the demographic variables with each of the attributes, which then reflect the conjoint tasks more accurately.

Hypothesis 2. There is a significant difference in the mean importance for financial rewards, expectations of success, job risk, pay risk and exerted effort (based on the participants' gender, past entrepreneurial experience and number of years of work experience).

\section{Research design Research approach}

Researchers normally use conjoint analysis in market research when they identify which of a product's attributes are most important and to what extent these attributes contribute to customers' decisions to buy specific products (Green \& Wind, 1975).

Respondents evaluate different combinations of attributes. This allows researchers to calculate the relative importance of the separate attributes. It is essentially an approach that resembles real life situations more closely than questionnaires or interviews do because it places respondents in situations where numerous attributes come into play when they make decisions (Orme, 2009).

It is important to note that the authors limited the number of attributes (independent variables) in this study. This is well within the recommended limit for a full profile conjoint analysis. Two levels of intensity (high $=1$ and low $=-1$ ) characterise these five attributes. This resulted in 32 unique profiles or scenarios.

In conjoint analysis, one can decide whether to use a fullfactorial design, which includes all possible combinations, or a reduced number of combinations by using a fractional factorial design (Green \& Srinivasan, 1990; Moore \& Holbrook, 1990).

Normally, researchers only use full factorial designs in situations where there are very few attributes and levels, thus resulting in a limited number of profiles (Orme, 2009). Considering that the study used five attributes with two levels each, the number of parameters the authors had to estimate was equal to six $(10-5+1)$. Based on Sawtooth software, it is good practice to have 1.5 to 3 times more observations than parameters.

In this case, the authors needed anywhere between nine $(6 \times 1.5)$ and eighteen $(6 \times 3)$ observations. Consequently, their $32\left(2^{\wedge} 5=32\right)$ observations would exceed the norm. Consequently, they regarded a fractional factorial design as the most suitable for this study (NIST/Sematech, 2010). Furthermore, the authors used an orthogonal design to ensure that the statistical correlation between the attributes is 0 (Orme, 2009; Monsen et al., 2010). 
Orthogonality allows one to estimate each attribute independently of the others. In this case, the five variables with two levels yielded $2^{5-1}=16$ profiles. An orthogonal design with 16 profiles is both symmetrical and balanced and falls within the scope of nine to 18 different scenarios. This is the recommended number of observations. A Microsoft Excel $^{\circledR}$ random number generator positioned the orthogonal design rows randomly and provided a unique sequence of questionnaire scenarios (NIST/Sematech, 2010).

Based on these specifications, the authors administered a survey, using a universal serial bus (USB) mass storage device, electronically to the sample of respondents. Previous research supports the use of Internet or web-enabled technology to collect conjoint analysis data (Sethuraman, Kerin \& Cron, 2005).

\section{Research participants and sampling}

Trying to identify samples of firms that practise CE strategies in various degrees (thereby reducing the restriction of range problems in the sample) was daunting. CE strategies may not be robust in firms. Furthermore, firms with highly developed entrepreneurial CE strategies may be few in number because using entrepreneurial CE strategies continuously may render these firms vulnerable to collapse (Ireland et al., 2009).

To counteract these sample identification challenges, and in order to select firms with varying levels of CE sophistication, the authors used the Technology Top 500 survey as a sampling frame because it highlights the technological prowess of South Africa's most innovative organisations.

Therefore, the authors used non-probability judgemental sampling depending on how the firms use technology and innovation to achieve their objectives (like maximising profits, gaining market share, creating niche markets or adding value for stakeholders) (Financial Mail, 2010).

Scrutinising these metrics served the purpose of assessing whether there was any evidence of CE practices in these organisations. Firms with higher CE practices would score highly on these metrics. Excluding cases with low levels of metrics, indicating low CE activity, provided an effective final sample of 158 respondents.

The authors sampled a wide range of businesses. The sample included various industry sectors (manufacturing, professional services, wholesale or retail and others). Sample parameters included firm size, which the authors measured using employment size class ( $80 \%$ of the sample had between 200 and 500 employees) and firm age (25\% were five to 10 years old, $51 \%$ were 11 to 20 years old and $23 \%$ were more than 20 years old).

In line with the study's objective, the target respondent was the individual employee. Characteristics of the respondents, presented in Table $1 \mathrm{a}$ and Table $1 \mathrm{~b}$, reveal some heterogeneity of the sample in terms of position occupied and work experience of the respondents.
TABLE 1a: Characteristics of respondents.

\begin{tabular}{lll}
\hline Sample characteristics & $f$ & $\begin{array}{l}\text { \% of } \\
\text { respondents }\end{array}$ \\
\hline Gender & 78 & 55 \\
Male & 63 & 45 \\
Female & & \\
Organisational rank & 21 & 15 \\
Frontline employee & 29 & 21 \\
Lower management & 44 & 31 \\
Middle management & 46 & 33 \\
Senior management & & \\
Career track & 54 & 38 \\
Management track & 14 & 10 \\
Technical track & 47 & 33 \\
Technical and management track & 26 & 18 \\
Not applicable & & \\
Entrepreneurial experience & 66 & 47 \\
No entrepreneurship experience & 40 & 28 \\
Start-up experience & 35 & 25 \\
CE venture experience & &
\end{tabular}

$f$, Frequency.

TABLE 1b: Characteristics of respondents.

\begin{tabular}{lll}
\hline Professional experience & M & SD \\
\hline Work experience (years) & 15.1 & 9.7 \\
Industry experience (years) & 11.5 & 9.3 \\
In current company (years) & 6.1 & 8.1 \\
Current position (years) & 2.7 & 3.6 \\
\hline
\end{tabular}

M, mean; SD, standard deviation.

\section{Measuring instrument: Decision scenarios}

Because this study used a previously established instrument as its basis (Monsen et al., 2010) and, because the authors drew the sample from a diversity of backgrounds with regard to gender, experience and so forth, they maintained content validity. Furthermore, a pilot study allowed for the preliminary establishment of construct validity and reliability by ensuring that the wording and instructions of the questionnaire were clear and understandable. After the pilot study, the authors used a 7-point rating scale that presented seven scenarios (where 1 represented 'no, will not participate' to 7 , which represented 'yes, will definitely participate').

Using the instrument, the authors asked the respondents to rate their likelihood of participation in a CE initiative for each one of the scenarios presented below. Each scenario comprised five attributes that reflected the hypotheses, which can be at high or low levels of intensity.

Using combinations of these five attributes, the authors asked each respondent to make a choice from a continuum of seven answers. The different parameters below informed the participation decision:

- Job risk = Low. There is a low probability $(5 \%)$ that you and the other project team members will lose your jobs if the project fails.

- Job risk $=$ High. There is a high probability $(50 \%)$ that you and the other project team members will lose your jobs if the project fails.

- Pay risk = Low. A minimal portion of your and the team members' salary (2\%) will be determined by achieving the 
project milestones and performance goals.

- Pay risk $=$ High. A major portion of your and the team members' salary (30\%) will be determined by achieving the project milestones and performance goals.

- Exerted effort = Low. Participation in the project will require a small amount of extra work from every member of the project team beyond your typical current working hours (30 minutes per day).

- Exerted effort $=$ High. Participation in the project will require a large amount of extra work from every member of the project team beyond your typical current working hours (two hours per day).

- Expectation of success = Low. Overall, you estimate that the project has a low probability of success (15\%).

- Expectation of success = High. Overall, you estimate that the project has a high probability of success (80\%).

- Financial reward = Low. If the project succeeds, you and the other team members will share a minimal portion of the project's profits (.5\%) from the first three years.

- Financial reward = High. If the project succeeds, you and the other team members will share a substantial portion of the project's profits (10\%) from the first three years.

\section{Research procedure}

The authors created dummy variables for the high and low levels for each of the five attributes and assigned values to represent a low level of intensity (0) and 1 for a high level of intensity. They then assigned each of the 16 scenarios a low and high level of intensity. The 16 scenarios, repeated for each respondent, led to a serial correlation for the $\mathrm{X}$ (independent) variable.

Arranging the 158 responses in a long column and running a single regression proved inadequate because the nature of the data inevitably led to highly correlated results. Such correlations lead to inflated statistical significance results like extremely high $t$-values and very low $p$-values (Hartmann \& Gardner, 1982).

Consequently, and consistent with the recommendation of Monsen et al. (2010), the authors regarded respondents with non-significant values $(p>.05)$ as inconsistent and removed them from the data set. They then checked the data set manually for all of the eliminated responses to determine consistency, or lack thereof, and to ensure valid decisions. They determined that these non-significant responses were nonsensical and that one could probably attribute them to respondents who randomly selected ratings in the survey despite the clear instructions the authors gave. The researchers eliminated six responses from the data set because the respondents recorded the same rating score for each scenario and 11 responses because of respondent inconsistency.

The final list of responses yielded 141 sets of data. Using the 'LINEST' function in Microsoft Excel ${ }^{\circledR}$, each response received a multiple regression coefficient. Using these coefficients, the authors calculated the part-worth utilities of the conjoint data. Each attribute with a low level of intensity received a 0 utility score, whilst the high level intensity level had either a positive or a negative 1 value depending on the effect that this particular attribute had on the overall regression equation.

\section{Data analysis}

The authors calculated part-worth utilities for each respondent, as well as the average part-worth utilities for the whole sample group and the utilities for the different demographic characteristics. This procedure entailed calculating attribute importances for each respondent individually and then averaging the importances, rather than calculating them from the averaged attribute utilities. These calculated utilities and importances are the final data the authors used to test the hypotheses.

A major concern about the validity of conjoint data is the very low degrees of freedom researchers normally use in conjoint studies (Green \& Srinivasan, 1978, 1990). Using the formula 'Degrees of Freedom = \# Profiles $(\mathrm{n})-$ \# Parameters $(\mathrm{T})^{\prime}$ ', the authors obtained 10 degrees of freedom. This reflected the study's six parameters and sixteen profiles.

In order to ensure internal data validity and that they were following the correct analytical procedures, the authors conducted several tests for robustness. A Microsoft Excel ${ }^{\mathbb{B}}$ based Visual Basic ${ }^{\circledR}$ for Applications (VBA) extracted all the data the authors needed to calculate Pearson correlations, where each respondent received a multiple linear regression equation. The authors ran separate regressions for each respondent and calculated the coefficient mean for estimating the overall attribute utility. Running a single regression would have produced very high $t$-values and extremely low $p$-values because of the serially correlated independent variables, as this article has mentioned earlier. By running separate regressions, an additional benefit was the calculation of individual $t$-values for each respondent's attributes. In order to establish whether the individual attributes were significant for the regression equations, the authors transformed the aggregation of $t$-values for all participants into a Z-score (Dechow, Huson \& Sloan, 1994; Douglas \& Shepherd, 2002).

The formula the authors used for the aggregation method was:

$z=\frac{1}{\sqrt{N}} \sum_{j=1}^{N} \frac{t_{j}}{\sqrt{k_{j} /\left(k_{j}-2\right)}} / \sqrt{1+(N-1) r}$

In this formula, $\mathrm{t}^{\mathrm{j}}=t$-value for individual $\mathrm{j}, \mathrm{k}^{\mathrm{j}}=10$ represents the degrees of freedom in regression for individual $j$ and $N=$ the number of responses in the sample. The Z-statistic distributes asymptotically as a standard normal variate (Dechow et al., 1994) and computes using the assumption of independence amongst employees (that is, $r=0$ ) (Douglas \& Shepherd, 2002). 


\section{Results \\ Conjoint part-worth utilities}

The final data set for 141 participants, based on the individual linear regressions, had an average R squared value of .80 and a standard deviation of .087, with minimum and maximum values of .63 and .98 respectively. The $p$-values of the data have a mean of .0078 with a standard deviation of .01 . As this article has mentioned earlier, an attribute (dependent variable) in the conjoint study will have a utility of 0 when it is at the low level of intensity. Therefore, only high levels of intensity will have associated utilities. Depending on the relationship (positive or negative) that the attributes have with the independent variable (willingness of participation), these utilities will have a positive or a negative value associated with them. The equation below is a representation of the average linear regression line the authors used for the data set:

$\mathrm{Y}($ Willingness of participation $)=2.80-1.06^{*}$

(Employment risk) - .31*(Pay risk) $-.45^{*}$

(Exerted effort $)+2.02 *$ (Success probability $)+$

$1.74^{*}$ (Financial reward)

[Eqn 2]

Using this equation for modelling the probability of $\mathrm{CE}$ participation required substitutions, depending on particular circumstances. For a high level of intensity on an attribute, 1 substitutes that specific attribute. If the attribute were at a low level of intensity, 0 would be the substitute. Therefore, based on this equation, the lowest possible Y-score the respondents achieved if employment risk, pay risk and exerted effort were high, whilst success probability and financial reward were low, was $\mathrm{Y}=.98$. Similarly, the respondents achieved the highest result of $Y=6.56$ with the same levels switched so that employment risk, pay risk and exerted effort are low, whilst success probability and financial reward are high. These results then corresponded with the instrument design in terms of obtaining a qualified 'no' or 'yes' for each response respectively.

Figure 2 presents the calculated utilities of the five attributes graphically. It is important to note that the magnitude of each attribute is directly proportional to the effect that it has on the participation equation. Figure 3 illustrates what happens to a participant's decision as attributes vary. For example, if all attributes were present at the low level of intensity, then the employee likelihood of participation would be 2.8 , which appears below the 'undecided line'. On the 'high level' side of the chart, several combinations show the potential uptake of a $\mathrm{CE}$ venture.

\section{Conjoint importances}

In order to calculate conjoint importances, the authors divided the sum of the ranges of each attribute's utility proportionally into 100 (Orme, 2009). Whilst importances are ratio-scaled, they are also specific to each study. Therefore, one cannot compare importances from one study with another. However, an attribute with an importance of $20 \%$ is twice as important as an attribute with a $10 \%$ importance.

Figure 4 presents the calculated conjoint importances for the different attributes.

\section{Regression values}

In order to assess the statistical validity of the five attributes, calculated from the individual regressions, the authors calculated the aggregate $t$-values that the Z-score represents.

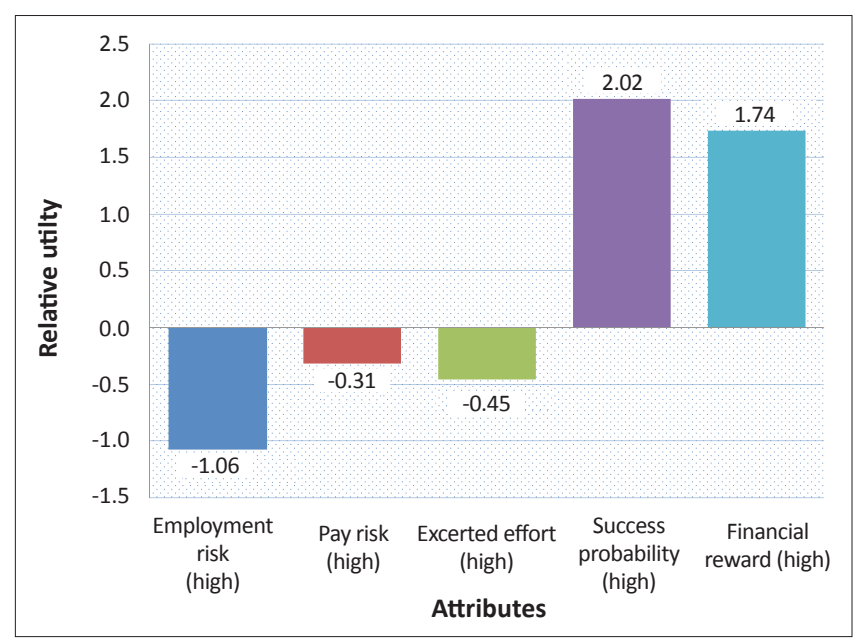

FIGURE 2: Part-worth utilities for each attribute.

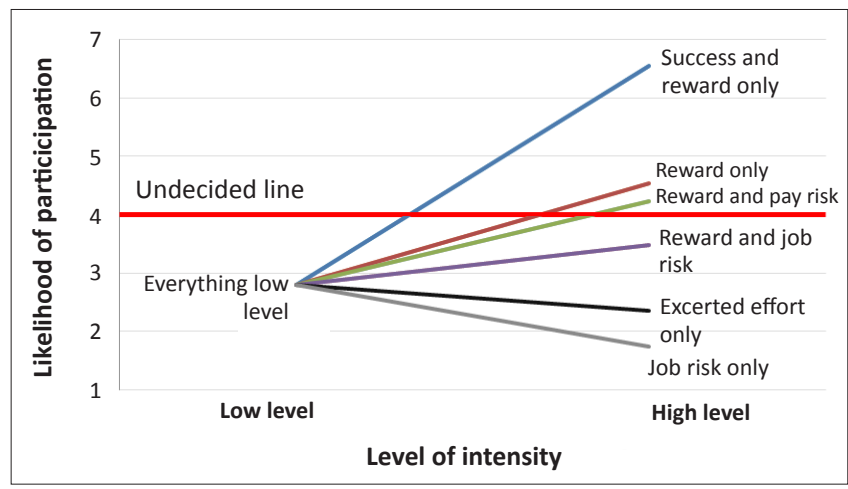

FIGURE 3: Likelihood of corporate entrepreneurship participation based on level of intensity.

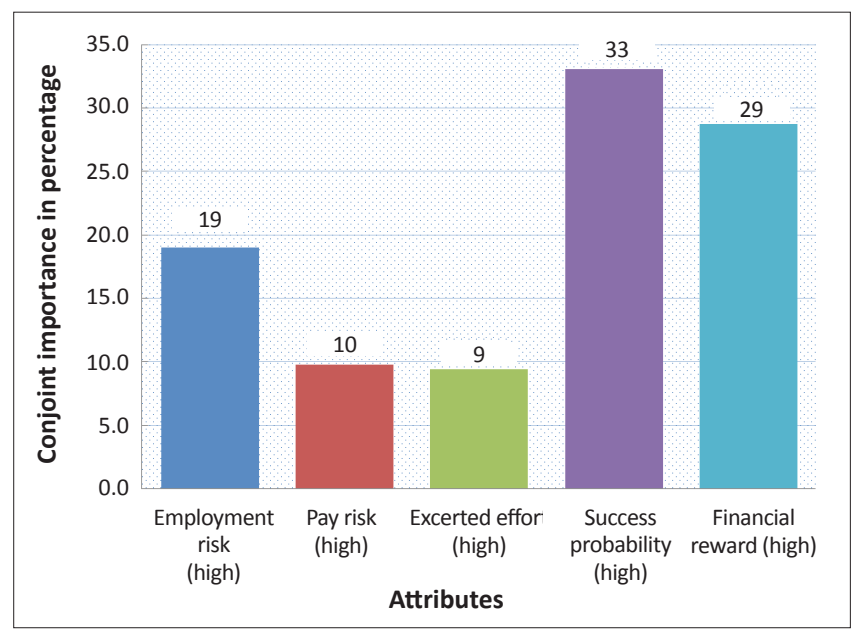

FIGURE 4: Conjoint importances for each attribute. 
The authors calculated these parameters using the 10 degrees of freedom they formulated earlier. The Z-scores, calculated from the aggregated $t$-values (Dechow et al., 1994), enabled the authors to calculate the corresponding $p$-values (all attributes of the regression are significant at the 99\% level).

Table 2 gives the Z-scores for each attribute for the 141 individual regressions.

\section{Hypotheses outcomes}

Results for Hypothesis 1, (see Table 2) show a positive relationship between the attributes of likelihood of participation and financial reward $(r=36.86 ; p<.01)$, as well as for the probability of success of venture $(r=45.71 ; p<.01)$. There is a negative relationship between the attributes of likelihood of participation and job risk $(r=-23.00 ; p<.01)$ as well as between pay risk $(r=-6.54 ; p<.01)$ and exerted effort $(r=-9.39 ; p<.01)$. Consequently, at the $99 \%$ confidence interval, there is support for Hypothesis 1 .

To test Hypothesis 2, the authors calculated differences in the part-worth utilities and mean importances of the various attributes using the demographics of gender, past entrepreneurial experience and number of years of work experience. Microsoft Excel ${ }^{\circledR}$ statistical formulas estimated $p$-values for a two-sample analysis of population means for all the combinations, as Hypothesis 2 specifies.

The authors structured the hypotheses combinations so that the null hypothesis assumes that the difference of the two means they investigated is 0 , whilst they structured the alternate hypothesis so that the difference between the two means is not 0 .

Table 3 gives the results of the mean differences in partworth utilities for all the attributes in terms of gender, entrepreneurial experience and work experience.

The authors used a $t$-test and found a significant difference between the mean utilities for the attribute job risk. This suggests that job risk affects respondents with past entrepreneurial experience less negatively compared to respondents without prior entrepreneurial experience $(t=2.120 ; p<.036)$.

TABLE 2: Risk and reward attributes - Z-scores and significance of regression coefficients

\begin{tabular}{llllll}
\hline Statistic & Employment risk & Pay risk & Exerted effort & Success probability & Financial reward \\
\hline Mean coefficient & -1.06 & -.31 & -.45 & 2.02 & 1.74 \\
Regression Z-score & -23.00 & -6.54 & -9.39 & 45.71 & 36.86 \\
$p$-value & $p<.01$ & $p<.01$ & $p<.01$ & $p<.01$ \\
\hline
\end{tabular}

TABLE 3: Comparing statistical means for each attribute's part-worth utility using demographic variables.

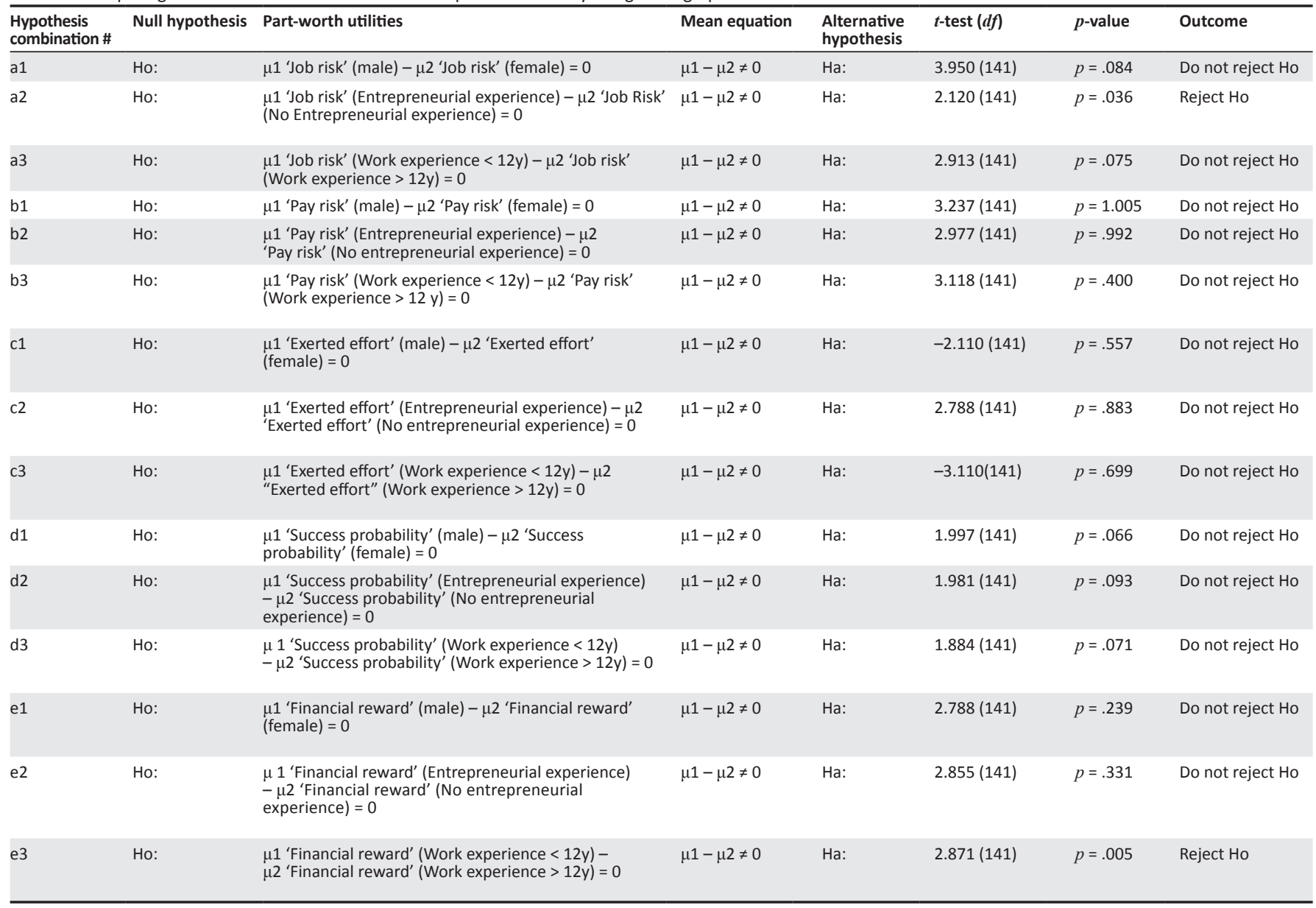

$\#$, number; $\mu$, mean; $y$, years; $d f$, degrees of freedom. 
The only other significant difference in part-worth utilities was on the financial risk attribute. Here the authors found that respondents with fewer than 12 years work experience put a lot more weight on the financial reward attribute compared to the respondents with 12 or more years of work experience $(t=2.871 ; p<0.005)$.

For all the other hypotheses combinations, the authors did not reject the null hypothesis in favour of the alternate hypothesis. The authors conducted the same procedure for conjoint importances for all the attributes and across demographics. Here they found similar significant differences for the same two attributes (not shown because of space limitations).

Overall, these results only partially support Hypothesis 2.

\section{Discussion}

Building on existing research, which found that employee participation is important for understanding CE activities, this study investigated the decision to participate in terms of rewards of various types as well as deterrents, which included risks factors like financial and job risks as well as extra effort requirements (Hornsby et al., 2009).

This study is one of the first to determine empirically which criteria employees use are significant when they decide to participate in CE activities. By presenting various scenarios to respondents, the authors analysed several attributes in different combinations in terms of their intensity levels by relying on dichotomous manipulations.

By measuring the relative importance one can attribute to CE participation per respondent, the authors found several significant positive correlations between the mean partworth utilities one can attribute to incentive sharing and to expectations of success, whilst they found significant negative correlations between the mean part-worth utilities attributable to job risk, pay risk and exerted effort.

Using the utilities that the authors calculated for each of the five attributes, their findings suggest that having a high level of intensity in these specific attributes can induce employees to be more or less likely to participate in CE initiatives. More specifically, the empirical evidence that emanated from this study was that the most important attribute is the 'probability of venture success'. 'Financial reward' follows as the second most important attribute.

As expected, the authors found that the attributes of 'job risk' and 'pay risk' were deterrents to participation in $\mathrm{CE}$ activities. The importance of the first attribute 'probability of venture success', with a utility value of 2.02 and importance level of $33 \%$, suggests that it determines the decision to participate above all the other attributes. Existing literature also emphasises that the second most important attribute is 'financial reward', with a utility value of 1.74 and importance level of $29 \%$. Researchers regard individual performance assessment and compensation as critical for CE participation (Kuratko et al., 2011).

The remaining attributes of 'job risk', which ranked third in terms of importance and had a utility value of -1.06 and a importance level of 19\%, 'pay risk' and 'exerted effort' were the lowest ranked attributes respectively. This shows that employees are reluctant to risk a portion of their pay and work extra hard, even if they believe that there is a chance to get involved in successful CE ventures and that the payouts will be fair.

The study also shows that prior entrepreneurial experience plays a significant role in two attributes. For the attribute 'job risk', there were significant differences in utilities and importances. There was a significant difference in mean score, at the $90 \%$ confidence level, for the 'probability of success' attribute in terms of importance.

These findings suggest that employees with past entrepreneurial experience are less concerned about 'job risk' and have a higher positive perception about 'probability of venture success' when it comes to participation in CE ventures. Perhaps employees with prior entrepreneurial experience are more confident about their ability to navigate the entrepreneurial process successfully, particularly because research shows that experience in the entrepreneurship domain includes having dealt with start-up problems like generating sales, developing marketing avenues and tactics, obtaining external financing and dealing with internal financial and general management issues (Wiklund, 1999).

\section{Limitations of the study and future research}

The present study focused only on individual financial reward. It did not consider different types of rewards, like group or organisation-level rewards and their effects on CE participation. The authors recommend this for future research (Gomez-Mejia, Welbourne \& Wiseman, 2000).

Furthermore, the study does not consider interaction effects, which requires more profiles. The present study considered only dichotomous (high/low) type manipulators. Using trichotomous (high-medium-low) type manipulators might yield data sets that are more comprehensive (Zenger \& Marshall, 2000).

\section{Implications of the study}

The results have contextual relevance because we know little about CE participation or CE in emerging economies (Bruton, Ahlstron \& Obloj, 2008; Luo, Zhou \& Liu, 2005; Urban, 2008). Emerging economies differ from western economies because rapid change characterises them and they have an institutional and market environment quite different to those in western economies (Yiu, Lau \& Bruton, 2007). For firms in emerging economies, the challenge to participate in the global economy of the 21st century will be to compete 
as world-class businesses where the focus is on high-value added human capital based on creativity and innovation that produces high-growth corporate ventures (Luiz, 2006; Urban, 2008).

Relevant to emerging economies is that recent research has found that intrapreneurship and independent entrepreneurship seem to be substitutes at the macro level. Large firms in high-income countries tend to display more entrepreneurial behaviour than do large firms in low-income countries (Bosma, Stam \& Wennekers, 2010). Much CE research focuses on large corporations and on the manufacturing sector, particularly in relation to high technology sectors. However, smaller firms may also have scope for significant CE activity. We need further theorisation and empirical analysis of these different contexts.

The study provides guidance to corporate managers and leaders who are interested in motivating their employees to undertake CE activities. The results give direction to employees who want to undertake CE ventures and give them a fair indication of what the maximum incentive is that they could expect whilst they consider commensurate risks.

Considering that CE sustainability depends on individual employees to undertake innovative activities (Hornsby et al., 2009), managers must design incentive contracts that consider the motivating attributes and the deterrents. Senior managers should try to reduce and manage the potential risks of participation and allow for increased employee independence for participating in CE activities (Douglas \& Shepherd, 2000).

The de sign of the present study, in terms of conjoint analysis, provides managers with a dashboard of possible attributes, according to which they can devise an optimal CE incentive strategy. Furthermore, based on the findings, an optimum design for an incentive system can maximise the probability of employee participation, whilst simultaneously reducing companies' financial costs and the perceived risks associated with CE ventures.

\section{Conclusion}

This study set out to determine empirically which criteria employees use when they decide to participate in $\mathrm{CE}$ activities.

The results show that the most important attribute that influences decisions to participate in CE is the probability of venture success, whilst financial reward follows closely. Furthermore, as the authors expected, job risk, pay risk and exerted effort are deterrents to CE participation. In addition, people with past entrepreneurial experience are less concerned about job risk and have more positive perceptions about the probability of CE success. The study is one of the first to provide direction to employees who want to undertake $\mathrm{CE}$ activities and offers them a fair indication of what the maximum incentive is that they could expect whilst they consider commensurate risks.

\section{Acknowledgements Competing interests}

The authors declare that they had no financial or personal relationship(s) that may have inappropriately influenced them when they wrote this article.

\section{Authors' contributions}

K.N. (University of the Witwatersrand) was responsible for the project design and execution, conducted the data analysis and contributed to the conceptual model. B.U. (University of the Witwatersrand) was the project leader. He assisted with conceptualising the study, with the literature review, the methodology and wrote the article.

\section{References}

Allen, R.E., Lucero, M.A., \& Van Norman, K.L. (1997). An examination of the individual's decision to participate in an employee involvement program. Group. Organizationa Management, 22, 117-123. http://dx.doi.org/10.1177/1059601197221008

Amit. R., Muller, E., \& Cockburn, I. (1995). Opportunity costs and entrepreneurial activity. Journal of Business Venturing, 10, 95-106. http://dx.doi. org/10.1016/0883-9026(94)00017-0

Antoncic, B. (2003). Risk taking in intrapreneurship: Translating the individual level risk aversion into the organizational risk taking. Journal of Enterprise Culture, 11(1) 1-23. http://dx.doi.org/10.1142/S0218495803000020

Antoncic, B. (2006). Impacts of diversification and corporate entrepreneurship strategy making on growth and profitability: A normative model. Journal of Enterprise Culture, 14, 49-63. http://dx.doi.org/10.1142/S0218495806000040

Antoncic, B., \& Hisrich, R.D. (2001). Intrapreneurship: construct refinement and crosscultural validation. Journal of Business Venturing, 16(5), 495-527.

Antoncic, B., \& Hisrich, R.D. (2003). Clarifying the intrapreneurship concept. Journal of Small Business Enterprise Development, 10(1), 7-17. http://dx.doi.org/10.1016/ S0883-9026(99)00054-3

Antoncic, B., \& Hisrich, R.D. (2004). Corporate entrepreneurship contingencies and organizational wealth creation. Journal of Management Development, 23(6), 518-550. http://dx.doi.org/10.1108/14626000310461187

Arnolds, C.A., \& Venter, D.J.L. (2007). The strategic importance of motivational rewards for lower-level employees in the manufacturing and retailing industries. The South African Journal of Industrial Psychology, 33(3), 15-23.

Barrick, M.R., \& Alexander, R.A. (1987). A review of quality circle efficacy and the existence of positive-finding bias. Personnel Psychology, 40(3), 579-592. http:// dx.doi.org/10.1111/j.1744-6570.1987.tb00616.x

Baum, J., \& Locke, E. (2004). The relationship of entrepreneurial traits, skill, and motivation to subsequent venture growth. Journal of Applied Psychology, 89, 587-598. http://dx.doi.org/10.1037/0021-9010.89.4.587, PMid:15327346

Bosma, N., \& Harding, R. (2006). Global Entrepreneurship Monitor. GEM 2006 Results. Babson and London Business School.

Bosma, N., Stam, E., \& Wennekers, S. (2010). Intrapreneurship - an International Study. EIM Research Report Intrapreneurship. Dutch Ministry of Economic Affairs.

Brown, T., Davidsson, P., \& Wiklund, J. (2001). An operalization of Stevenson's conceptualisation of entrepreneurship as opportunity-based firm behavior. Strategic Management Journal, 22, 953-968. http://dx.doi.org/10.1002/smj.190

Bruton, G.D., Ahlstrom, D., \& Obloj, K. (2008). Entrepreneurship in emerging economies: where are we today and where should the research go in the future. Entrepreneurship Theory and Practice, 32(1), 1-14. http://dx.doi.org/10.1111/ Entrepreneurship Theory and
j.1540-6520.2007.00213.x

Buch, K. (1991). Quality circles in a unionized setting: Their effect on grievance rates. Journal of Business \& Psychology, 6(1), 147-154. http://dx.doi.org/10.1007/ BF01013690

Burgelman, R.A. (1983). A process model of internal corporate venturing in the diversified major firm. Administrative Science Quarterly, 28, 223-244. http:// dx.doi.org/10.2307/2392619

Burns, P. (2004). Corporate Entrepreneurship: Building an Entrepreneurial Organization. Palgrave Macmillan: Basingstoke.

Cassar, G. (2006). Entrepreneur opportunity costs and intended venture growth. Journal of Business Venturing, 21, 610-632. http://dx.doi.org/10.1016/j. jbusvent.2005.02.011

Covin, J.G., \& Kuratko, D.F. (2008). The concept of corporate entrepreneurship. In V. Narayanan \& G. O'Connor (Eds.), The Blackwell Encyclopaedia Of Technology And Innovation Management. Oxford, UK: Blackwell Publishers. PMid:17321717 
Covin, J.O., \& Miles, M.P. (1999). Corporate entrepreneurship and the pursuit of competitive advantage. Entrepreneurship Theory and Practice, 23(3), 47-63.

Covin, J.G., \& Miles, M.P. (2007). Strategic use of corporate venturing. Entrepreneurship Theory and Practice, 31(2), 183-207. http://dx.doi.org/10.1111/j.1540$6520.2007 .00169 x$

Covin, J.G., \& Slevin, D.P. (1989). Strategic planning of small firms in hostile and benign environments. Strategic Management Journal, 10, 75-87. http://dx.doi. org/10.1002/smj.4250100107

Damanpour, F. (1991). Organizational innovation: A meta-analysis of effects of determinants and moderators. Academic Management Journal, 34(3), 555-590. http://dx.doi.org/10.2307/256406

Dechow, P.M., Huson, M.R., \& Sloan, R.G. (1994). The effect of restructuring charges on executives' cash compensation. Accounting Review, 69(1), 138-156.

Dess, G.G., Ireland, R.D., Zahra, S.A., Floyd, S.W., Janney, J.J., \& Lane, P.J. (2003). Emerging issues in corporate entrepreneurship. Journal of Management, 29(3), 351. http://dx.doi.org/10.1016/S0149-2063 03_00015-1

Dess, G.G., Lumpkin, G.T., \& McGee, J.E. (1999). Linking corporate entrepreneurship to strategy, structure, and process: suggested research directions. Entrepreneurship Theory and Practice, Winter, 85-101.

Douglas, E.J., \& Shepherd, D.A. (2000). Entrepreneurship as a utility maximizing response, Journal of Business Venturing, 15, 231-251. http://dx.doi.org/10.1016/ S0883-9026(98)00008-1

Douglas, E.J., \& Shepherd, D.A. (2002). Self-Employment as a career choice: attitudes, entrepreneurial intentions, and utility maximization. Entrepreneurship Theory and Practice, 26, 81-91.

Drucker, P. (1979). The Practice of Management. Pan books Ltd: London.

Fehr. E., \& Schmidt, K.M. (2007). Adding a stick to the carrot? The interaction of bonuses and fines. American Economic Review, 97, 177-181. http://dx.doi. org/10.1257/aer.97.2.177

Financial Mail. (2010). Top Companies 2010, Financial Mail, 24th June. Retrieved March 03, 2011 from www.fm.co.za/Article.aspx?id=112850

Folta, T.B., Delmar, F., \& Wennberg, K. (2010). Hybrid entrepreneurship. Managemen Science, 56(2), 253-269. http://dx.doi.org/10.1287/mnsc.1090.1094

Fuglsang, L., \& Mattsson, J. (2011). Making sense of innovation: A future perfect approach. Journal of Management \& Organisation, 17, 448-458. http://dx.doi. org/10.5172/jmo.2011.17.4.448

Gomez-Mejia, L.R., Welbourne, T.M., \& Wiseman, R.M. (2000). The role of risk sharing and risk taking under gain sharing. Academic Management Review, 25(3), 492507.

Grandori, A., Giordani, L.G., \& Hayton, J. (2011). Organizing entrepreneurship. Routledge. New York.

Green, P.E., \& Srinivasan, V. (1978). Conjoint analysis in consumer research: issues and outlook. Journal of Consumer Research, 5(2), 103-123. http://dx.doi. org/10.1086/208721

Green, P.E., \& Srinivasan, V. (1990). Conjoint analysis in marketing: new developments with implications for research and practice. Journal of Marketing, 54, 3-19. http://dx.doi.org/10.2307/1251756

Green, P.E., \& Wind, Y. (1975). New way to measure consumers' judgments. Harvard Business Review, 53(4), 107-117.

Hartmann, D.P., \& Gardner, W. (1982). A cautionary note on the use of probability values to evaluate inter-observer agreement. Journal of Applied Behaviour Analysis, 15(1), 189-201. http://dx.doi.org/10.1901/jaba.1982.15-189, Analysis, $15(1)$
PMCid:1308259

Hornsby, J.A., Kuratko, D.F., Shepherd, D.A., \& Bott, J.P. (2009). Managers' corporate entrepreneurial actions: Examining perception and position. Journal of Business Venturing, 24, 236-247. http://dx.doi.org/10.1016/j.jbusvent.2008.03.002

Hornsby, J.S., Kuratko, D.F., \& Zahra, S.A. (2002). Middle managers' perception of the internal environment for corporate entrepreneurship: Assessing a measurement scale. Journal of Business Venturing, 17, 253-273. http://dx.doi.org/10.1016/ S0883-9026(00)00059-8

Ireland, R.D., Covin, J.G., \& Kuratko, D.F. (2009). Conceptualizing Corporate Entrepreneurship Strategy. Entrepreneurship Theory and Practice, 33(1), 19-46. http://dx.doi.org/10.1111/j.1540-6520.2008.00279.x

Khandwalla, P.N. (1977). The Design of Organizations. Harcourt Inc: New York.

Kuratko, D.F., \& Welsch, H.P. (2001). Strategic Entrepreneurial Growth. Harcourt College: Fort Worth, TX.

Kuratko, D.F., \& Audretsch, D.B. (2009). Strategic entrepreneurship: exploring different perspectives of an emerging concept. Entrepreneurship Theory and Practice, 33(1), 1-17. http://dx.doi.org/10.1111/j.1540-6520.2008.00278.x

Kuratko, D.F., Hornsby, J.S., \& Goldsby, M.G. (2004). Sustaining corporate entrepreneurship: a proposed model of perceived implementation/outcome comparisons at the organizational and individual levels. International Journal of Entrepreneurship and Innovation, 5(2), 77-89. http://dx.doi. org $/ 10.5367 / 000000004773863237$

Kuratko, D.F., Hornsby, J.S., Naffziger, D.W., \& Montangno, R.V. (1993). Implement entrepreneurial thinking in established organizations. SAM Advanced Management Journal, 58(1), 28-39.

Kuratko, D.F., Ireland, R.D., Covin, J.G., \& Hornsby, J.S. (2005). A model of middlelevel managers' entrepreneurial behaviour. Entrepreneurship Theory and Practice 29(6), 699-716. http://dx.doi.org/10.1111/j.1540-6520.2005.00103.x, http:// dx.doi.org/10.1111/j.1540-6520.2005.00104.x

Kuratko, D.F., Morris, M.H., \& Covin, J.C. (2011). Corporate Innovation and entrepreneurship. 3rd Edition. South Western.Canada. PMid:21430120
Liu, S.S., Luo, X., \& Shi, Y. (2003). Market-oriented organizations in an emerging economy: A study of missing links. Journal of Business Research, 56, 481-491. http://dx.doi.org/10.1016/S0148-2963(01)00265-X

Lohrke, F.T., Holloway, B.B., \& Woolley, T.W. (2010). Conjoint analysis in entrepreneurship research: A Review and Research Agenda. Organizational Research Methodology, 13, 16-30. http://dx.doi.org/10.1177/1094428109341992

Luo, X., Zhou, L., \& Liu, S.S. (2005). Entrepreneurial firms in the context of China's transition economy: an integrative framework and empirical examination. Journal of Business Research, 58(3), 277-284. http://dx.doi.org/10.1016/S01482963(03)00159-0

Luiz, J. (2006). Managing business in Africa. Practical management theory for an emerging market. Oxford University Press. South Africa.

Martins, E., \& Martins, N. (2002). An organizational culture model to promote creativity and innovation. South African Journal of Industrial Psychology, 28(4), 58-65.

Miller, R.W., \& Prichard, F.N. (1992). Attributes associated with workers' inclination to participate in an employee involvement program. Group Organizationa Management, 17(4), 414. http://dx.doi.org/10.1177/1059601192174007

Monsen, E., Patzelt, H., \& Saxton, T. (2010). Beyond simple utility: incentive design and trade-offs for corporate employee-entrepreneurs. Entrepreneurship Theory and Practice, 34, 105-130. http://dx.doi.org/10.1111/j.1540-6520.2009.00314.x

Moore, W.L., \& Holbrook, M.B. (1990). Conjoint analysis on objects with environmentally correlated attributes: The questionable importance of representative design. Journal of Consumer Research, 16(4), 89-97. http://dx.doi. org/10.1086/209234

Morris, M., Davis, D.L., \& Allen, J.W. (1994). Fostering corporate entrepreneurship: cross cultural comparisons of the importance of individualism versus collectivism. Journal of International Business Studies, 25, 65-90. http://dx.doi.org/10.1057/ palgrave.jibs.8490849

Morris, M.H., \& Kuratko, D.F. (2002). Corporate Entrepreneurship. Harcourt College Publishers: Florida.

Morris, H.M., Kuratko, D.F., \& Covin, J.G. (2008). Corporate entrepreneurship \& innovation. South-Western, Mason.

Muller, Y., \& Rothmann, S. (2009). Sense of coherence and employees' perceptions of helping and restraining factors in an organisation. South African Journal of Industrial Psychology, 35(1), 1-10.

Nanda, R., \& Sorensen, J.B. (2010). Workplace peers and entrepreneurship. Management Science, 56(7), 1116-1126. http://dx.doi.org/10.1287/ mnsc.1100.1179

Neill, S., \& York, J.L. (2011). The entrepreneurial perceptions of strategy makers: Constructing an exploratory path in the pursuit of radical growth. Journal of Business Research

NIST/Sematech. (2010). Summary tables of useful fractional attributerial designs e-Handbook of statistical methods. National Institute of Standards and Technology.

Norris, D.R., \& Cox, J.F. (1987). Quality circle programmes: volunteering for participation. Journal of Occupational Behaviour, 8(3), 209-217. http://dx.doi. participation. Journal of Occupd

dendaal, A., \& Roodt, G. (1998). Corporate culture and participation: independent constructs? Journal of Industrial Psychology, 24(3), 14-21.

Onyishi, I.E., \& Ogbodo, E. (2012). The contributions of self-efficacy and perceived organizational support when taking charge at work. South African Journal of Industrial Psychology, 38(1), 1-11.

Orme, B.K. (2009). Getting started with conjoint analysis. Research Publishers, LLC.

Phan, P.H., Wright, M., Ucbasaran, D., \& Tan, W.L. (2009). Corporate entrepreneurship: Current research and future directions. Journal of Business Venturing, 24(3), 197205. http://dx.doi.org/10.1016/j.jbusvent.2009.01.007

Phelps, E. (2009). Thoughts on a crisis. future of capitalism - debate. Financial Times, May 12.

Pinchot, G. (1985). Intrapreneuring: Why you don't have to leave the corporation to be an entrepreneur. Harper and Row: New York.

Schindehutte, M., Morris, M.H., \& Kuratko, D.F. (2000). Triggering events, corporate entrepreneurship and the marketing function. Journal of Marketing Theory and Practice, 8(2), 18-20.

Schumpeter, J.A. (1934). The theory of economic development. Harvard University Press: Cambridge, MA.

Sethuraman, R., Kerin, R.A. \& Cron, W.L. (2005). A field study comparing online and offline data collection methods for identifying product attribute preferences using conjoint analysis, Journal of Business Research, 58,602-610. http://dx.doi. using conjoint analysis. Journal of Bus
org/10.1016/j.jbusres.2003.09.009

Shepherd, D. (2011). Multilevel entrepreneurship research: opportunities for studying entrepreneurial decision making. Journal of Management, 37, 412-420.

Shepherd, D.A., \& Zacharakis, A. (1997). Conjoint analysis: A window of opportunity for entrepreneurship research. Advances in Entrepreneurship and Firm Emergence Growth, 3, 203-248. http://dx.doi.org/10.1177/0149206310369940

Sirmon, D.G., Hitt, M.A., \& Ireland, R.D. (2007). Managing firm resources in dynamic environments to create value: looking inside the black box. Academy of Management Review, 32(1), 273-292. http://dx.doi.org/10.5465/ AMR.2007.23466005

Sykes, H.B. (1992). Incentive compensation for corporate venture personnel Journal of Business Venturing, 7(4), 253-265. http://dx.doi.org/10.1016/08839026(92)90001-8

Tang, L., \& Koveos, P.E. (2004). Venture entrepreneurship, innovation entrepreneurship, and economic growth. Journal of Developmental Entrepreneurship, 9, 161-171. 
Urban, B. (2008). The prevalence of entrepreneurial orientation in a developing country: juxtapositions with firm success and South Africa's innovation index. Journal of Developmental Entrepreneurship, 13(4), 425-443. http://dx.doi.
org/10.1142/S108494670800106X

Urban, B. (2011). Entrepreneurial networking differences: an ethnic in-group and outgroup analysis. South African Journal of Industrial Psychology, 37(1), 1-14.

Valoyi, E.G., Lessing, B.C., \& Schepers, J.M. (2000). Participation in decision making. Journal of Industrial Psychology, 26(3), 32-38.

Verma, A., McKersie, R.B. (1986). Employee involvement: The implications of noninvolvement by unions. Industrial Labour Relations Review, 40(4), 556-568. $\mathrm{http}: / / \mathrm{dx}$.doi.org/10.2307/2524058
Wiklund, J. (1999). The sustainability of the entrepreneurial orientation-performance relationship. Entrepreneurship Theory and Practice, 24(1), 37-48.

Yiu, D.W., Lau, C., \& Bruton, G.D. (2007). International venturing by emerging economy firms: the effects of firm capabilities, home country networks, and corporate
entrepreneurship. Journal of International Business Studies, 38(4), 519-540. http://dx.doi.org/10.1057/palgrave.jibs.8400278

Zahra, S.A. (1993). A Conceptual model of entrepreneurship as firm behavior: a critique and extension. Entrepreneurship Theory and Practice, 17(4), 5-21.

Zenger, T.R., \& Marshall, C. (2000). Determinants of incentive intensity in groupbased rewards. Academic Management Journal, 43(2), 149-163. http://dx.doi. org/10.2307/1556373 